\title{
Study on Rural Human Resource Development under View of Rural Regional Economic Development
}

\section{Bo Wu}

\section{School of Economics and Management, Chongqing Normal University, Chongqing, 401331, China}

\begin{abstract}
Rural human resource development is a comprehensive and systematic job involving culture, market and government. It is necessary to improve human resource quality and then promote economic development through training and education. With economic innovation and development, higher requirements are put forward for peasants in terms of professional skills and comprehensive quality. China has a late start in the aspect of human resources development. There are both many opportunities and numerous barriers in market, system and policy in the utilization and development process. China should combine actual conditions in Chinese rural areas and refer to foreign excellent cases to formulate human resource development mode, serve for modernization construction and promote rapid economic development. Rural economic development and human resource development are of dialectical unity relationship. Only when human resource is developed can economic development be promoted. Meanwhile, economic development provides financial and material support for human resource development.
\end{abstract}

Key words: rural human resource; development; economic development

Human resource is a special resource, different from other material resources. It has distinct characteristics. Rural human resource development plays an important role in economic construction.

I. Principle, objective and connotation of rural human resource development

1. Principle of rural human resource development

Rural human resource should be developed in accordance with rural 
characteristics and different principles. Firstly, multilayer principle should be implemented. It is required to cultivate different types of rural talents who master different techniques and form multilayer talent structure. Secondly, adjustment principle should be abided by. Adjustable talent development should be carried out according to economic development and industrial structure changes. Thirdly, long-term principle. Rural human resource development is a huge project. Long-term development idea should be established to carry out human resource development effectively. Fourthly, practicability principle. It is required to rationally arrange and improve peasants' operation level and comprehensive quality, and reach the purpose of human resource development contents.

2. Objective of rural human resource development

Rural human resource development needs to reach the four objectives:

2.1 Enhance cultural quality, moral quality, professional skills and management skills of rural human resource, meet rural construction need and drive economic development through strengthening technical education, adult education and basic education.

2.2 Control the population size through enhancing family planning. This contributes to sustainable development of human resource.

2.3 Achieve optimal allocation and fully employment of human resources through adjusting irrational distribution of human resources in regions, employment and knowledge structure.

2.4 More effectively carry out human resource development without any worry through establishing rural guarantee system.

3. Significance of rural human resource development

Firstly, quality and quantity of human resources should be united. Quantity is the foundation of human resource development, while quality is the core. Secondly, human resource development owns certain plasticity and reproducibility. The quality of human resources can improve through education. Rural human resources are the sum of mental and physical strength of rural population within certain range, and the sum of labor force able to give play to intelligence and physical strength through 
education. The quantity of rural human resources refers to the population quantity consisting of labor force. The quality refers to technology, knowledge and intelligence level of rural human resources. The quality is generally reflected in physique and cultural level.

\section{Background of rural regional economic development}

The purpose of comprehensive rural reform can be achieved through building a

new socialist countryside and boosting rural economic development. Currently, urban-rural gap is still large in China. Dual structure restricts economic development. Dual structure means two types of living conditions, life styles and life ideas exist in a country. Urban and rural consumption, income and education level have a huge gap. It is imperative to speed up rural economic construction. China's rural economic development is in a transformation period. The life transforms to development type from subsistence type. Personal consumption expenditures grow rapidly. To change current situation of low-quality human resources in rural areas, it is required to carry out effective and rational human resource development. With continuous development of economic construction, the price of industrial and agricultural products is narrowing. The conditions of supporting rural construction by urban areas have basically owned.

\section{Significance of rural economic development}

Development of rural regional economy is the requirement of constructing a well-to-do society. Rural areas should speed up economic construction on the basis of solving basic living needs, increase peasants; income and promote economic development. During economic construction, the problems of rural areas, agriculture and peasants should be solved. For a long time, the main problems hindering rural economic development are the problems of rural areas, agriculture and peasants. Rural education and living level is lower than that of cities. Modernization course is 
slow. The contradictions and problems can be solved through strengthening economic construction. Rural development lag situation can be altered through increasing peasants; income. It is also required to coordinate interests of each party, perfect management system and build an orderly and stable society through breaking dual structure of urban and rural economies. Improving peasants; living standard has extraordinary practical significance for narrowing urban-rural gap and accelerating rural economic development.

\section{Analysis of advantages of rural economic development and rural human} resource

4.1 Peasants' conscious and conscious human resource development

In order to meet needs of product and industrial structure and adapt fierce market competitions, peasants gradually realize the importance of boosting professional skills and cultural quality, so they spontaneously carry out activities to develop human resources. It is necessary to enhance technical training for peasants, establish technological association, conduct specialized operation and walk the way of industrial development. This can boost peasants' quality, increase heir income and make contributions to economic development. Currently, rural human resource development has acquired many achievements, mainly including four aspects. Firstly, educational institutions are continuously performed. Multiple skill training and vocational education form. Secondly, peasants' living standards have promoted. Medical conditions have improved. Thus, peasants’ physical quality and educational degree enhance continuously. Thirdly, supply and demand mechanism of labor market has been formed step by step. Fourthly, the government breaks though urban and rural boundary, lead rural labor force into multiple industries and promotes joint development of cities and rural areas through guidance and support.

4.2 Policy advantage of economic development and human resource development

With economic system reform and social development, the state attaches great importance to rural human resource, and strives to facilitate human resource 
development, increase peasants' economic income and improve quality of rural human resources. In terms of human resource development, the government adopts some effective measures to boost cultural level of rural labor force, including popularization of nine-year compulsory education and promotion of vocational training and adult education. Various kinds of technical training classes form systematic educational organizations from top to bottom, cultivate talents suitable for rural development, promote strategic objective of promoting agriculture by applying scientific and technological advances, boost peasants’ professional level and cultural knowledge and facilitate rapid development of rural economy.

\section{Relationship between rural economic development and rural human resource development}

As rural development and progress, human resource plays a decisive role for economic growth. Human resource can effectively develop economy. Economic development can protect and support human resource. The two mutually promote.

5.1 Rural human resource development provides talents for economic development

China is a large agricultural country with numerous peasants. Rural human resource development can provide motive power for rural economic construction. Cultivation of peasants to become talents owning techniques and culture can drive rural economic development. Accumulation of human resource capital will become an economic growth point of rural areas and provides talent guarantee and technical support for rural development.

5.2. Rural economic construction needs wide-range human resource development

Modern rural construction needs talents with high techniques and strong professional knowledge to achieve industrial benefits. The first problem to be solved is to improve comprehensive quality of labor force and develop human resources.

5.3 Rural human resource development can further develop rural economy

Peasants own low skills, low culture and poor development ideal. These have 
become major factors influencing rural economic development. To develop rural economy, modernization and industrialization must be achieved. To achieve agricultural modernization, socialization, operation scale, enterprise management and professional production must be fulfilled. In agriculture industrialization, sales personnel and product procedures must possess cultural quality. Rural economic modernization and industrialization development puts forward higher requirements for labor force. Firstly, labor force should have knowledge in multiple aspects such as operation, management, science and technology and satisfy the demand or talents with knowledge diversity. Secondly, laborers should own professional quality. Modern agriculture needs to drive development of agricultural technicalization, increase output, quality and added value of agricultural products through accumulating human resources and boosting quality of labor force. This requires education and training of laborers, improving their technological level and integrated skills, and boosting sustainable development of agricultural economy.

\section{Opportunity analysis of rural economic development and human resource}

Through analysis of current situation of rural economic development and human resources, it can be seen that economic development and human resource development are in key rising period of stable, continuous and healthy development and will usher in prosperous development opportunities.

6.1 Implement overall development of urban and rural areas and drive rapid development of rural regional economy

According to strategic thought of overall development, it is required to comprehensively promote the level of agriculture science and technology, perfect the policies benefiting the people, improve people's livelihood, narrow urban-rural gap, provide favorable policy support and social environment, strive to develop rural human resource and drive rural economic development.

6.2 The government enhances support of "rural areas, agriculture and presents" 
and promotes economic development

"Rural areas, agriculture and presents" play an important guarantee role in achieving economic development and building a well-to-do society. To actively develop human resources and seize the policy of "rural areas, agriculture and presents" is an effective way to solve current problems of low quality of human resources and irrational structure. The government cancels agricultural tax, implements compulsory education and rural cooperative medical service, and relieves peasants; burden. On the one hand, these protect peasants' enthusiasm, boost rural industrial development and facilitate human resource development. On the other hand, these liberate labor force resources, create opportunities for economic development, human resource utilization and development and build new villages combining social benefit and economic benefit as well as urban and rural development.

6.3 Stable and rapid economic development is economic foundation of human resource development

China's economy fulfils rapid development on the basis of keeping favorable stability. Especially after joining WTO, China makes the best of Chinese and foreign markets, introduces techniques, attracts capital, keeps stable growth and provides soiled economic foundation for human resource development.

6.4 Develop the tertiary industry and lay a foundation for human resource development

The tertiary industry is based on services and characterized by rapid development, wide coverage and large attraction capacity. It can communicate urban culture, promote comprehensive quality of human resources and boost economic development.

VII. Functions of economic development on rural human resource development

7.1 Rural economic development provides power for human resource development

Development of rural economy with market as the orientation, technology as the 
guarantee and benefit the objective needs more peasants with professional quality. Continuous economic development forces peasants to update their ideas, learn knowledge, master techniques and receive training. Economic growth works externally and promotes development or rural human resource.

7.2 Develop rural human resources to adapt needs of rural economic development

Rural modernization and industrialization are the problems needing to be solved during economic development. Rural human resource development is the basis and objective requirement for achieving modernization and industrialization. It is required to promote quality, output and added value of agricultural products and increase agricultural economic benefits through refinement and professional ways. This requires a large number of talents with professional quality and cultural knowledge. It is necessary to train talents mastering management skills and understanding science to develop rural economy through human resource development and continuously study.

7.3. Rural economic development provides necessary market guidance for rural human resource development

Currently, Chinese human resource has the phenomenon of irrational technology and knowledge structure. Utilization and development ratios of rural human resource are low. Rural economic development will change surplus labor employment and industrial structure and provide necessary guidance mechanism for utilization and development of rural labor force.

7.4 Rapid development of rural economy provides certain capita support for human resource development

Human resource development is a long-term project in need of huge financial support. Art present, rural income is low and education investment is small. Financial expenditure used for peasants' basic education is relatively poor. This restricts human resource development. To develop rural economy, on the one hand, it is required to increase financial income and expenditure or peasants' education; on the other hand, if peasants' income rises, they will increase expenditure in education for themselves and their families so as to promote the course of human resource development. 


\section{Conclusions}

Rural human resource development can alter fixed economic growth pattern of rural areas. It is the foundation of rural economic growth and also driving force of sustainable economic development. On the way of constructing new countryside, human resource development can cultivate a group of new peasants able to operate, master techniques and own culture. Therefore, the study on rural human resource development mode has profound significance for whole social progress and rural economic development.

\section{Acknowledgments}

This paper is one of the phased achievements of national social science fund project "study on synergetic promotion of 'Wuhua' under mountain economic cluster development” (14XJL002), 2014.6-2016.6

\section{References}

[1] Wang Xiaoyuan, China's rural human resource development and new rural construction [J]. Guide of Sci-tech Magazine, 2011(35)

[2] Wei Derong, Study ion countermeasures of rural human resource development in China [J]. Technological Pioneers, 2013(07)

[3] Li Kangyou, Discussion on rural human resource development under view of new rural construction [J]. Beijing Agriculture, 2011(03)

[4] Shu Xielan, Research of rural human resource problems in Guangdong [D]. Guangdong: Guangdong Ocean University, 2012

[5] Dai Guowen, Study on rural human resource development in view of new rural construction [D]. Heilongjiang: Northeast Agricultural University, 2012

[6] Zhang Taicheng, Liu Jiagui, Harmonious development of rural regional economy and construction of socialism new countryside [J]. Agricultural Economy, 2008(04) 